\section{No maternal transmission?}

SIR - Recent reports in the media of the outcome of a long-term study of the incidence of bovine spongiform encephalopathy (BSE) in the offspring of cows affected with BSE have widely assumed that these data show evidence of maternal transmission of BSE. That maternal transmission occurs in BSE has been incorporated in a recent modelling of the epidemic of $\mathrm{BSE}^{1}$, and data from this study and the supposition that maternal transmission occurs have been taken up by politicians in Britain and Europe in arguing about the best way to restore confidence in beef throughout Europe.

The use of these data is premature, as the full details of the maternal transmission experiment are not yet published. So far, we know from the Spongiform Encephalopathy Advisory Committee that, of 276 calves born to dams that subsequently died of BSE, 42 have themselves developed BSE, while, of 276 calves born to dams that did not get BSE, only 13 have developed BSE.

How might this difference have arisen? Three possibilities come to mind: (1) selection bias in the way these calves were acquired, (2) genetic susceptibility to infection with the agent of BSE and (3) transmission of the agent from the incubating (but not overtly sick) dam to the offspring. The numerical data, in the gross terms described, cannot differentiate between genetic susceptibility and maternal transmission. The calves involved were born around 1988, when exposure to contaminated feedstuff was high. The dams of these animals would also have been exposed to the feed-borne contamination which began in 1982 . If there was a difference in genetic suceptibility to feed-borne infection between the affected and unaffected dams, this would also be apparent in the offspring, leading to a higher rate in the offspring of affected compared to unaffected dams. To show convincingly that maternal transmission was occurring, these offspring would have to have been unexposed to agent from feedstuff.

So why are the data interpreted solely as evidence for maternal transmission? The answer probably lies in the widespread belief in maternal transmission in scrapie which persists despite new data that indicate that "there is no strong evidence for simple maternal or paternal transmission of disease [scrapie] other than inheritance of $\operatorname{PrP}$ genotype"2. Our reanalysis of the original data used to support maternal transmission shows no deviation from genetic inheritance of scrapie, and no evidence for maternal transmission in any other form of spongiform encephalopathy ${ }^{3}$. Furthermore, there is no established mechanism by which maternal transmission would occur. Data on infectivity in blood and placenta in sheep $^{4,5}$ are inadequate, and experiments have failed to detect infectivity in milk or any tissue outside the central nervous system in field cases of $\mathrm{BSE}^{6}$. Genetic involvement in prion disease is well established. In addition to point mutations in the $\operatorname{Pr} P$ gene which determine disease, homozygosity at codon 129 of the PrP gene increases susceptibility to iatrogenic and sporadic Creutzfeldt-Jakob disease ${ }^{7,8}$, and transgenic experiments have shown that homology between the prion protein molecules produced by each allele is important in pathogenesis ${ }^{9}$.

Although some analysis of the $\operatorname{PrP}$ gene in BSE-affected cattle has been undertaken ${ }^{10}$, the gene has not been studied extensively. Genetic influences outside the $\operatorname{Pr} P$ gene may also be important in determining which of a very large number of exposed animals succumb to BSE. Epidemiological analysis of BSE suggests that genetic influences may be occurring, but this cannot be definitively proved ${ }^{11}$. In these circumstances, it would be foolish to assume that maternal transmission occurs in BSE, especially when decisions of great economic and political importance are at stake.

\section{R. M. Ridley}

\section{H. F. Baker}

Department of Experimental Psychology,

Downing Street,

Cambridge CB2 3EB, UK

1. Anderson, R. M. et al. Nature 382, 779-788 (1996).

2. Hunter, N. et al. Arch. Virol. 141, 809-824 (1996).

3. Ridley, R. M. \& Baker, H. F. Br. Med. J. 311, 1071-1075 (1995).

4. Hadlow, W. J., Kennedy, R. C. \& Race, R. E. J. Infect. Dis. 146, 657-664 (1982)

5. Pattison, I. H., Hoare, M. N., Jebbett, J. N. \& Watson, W. A. Vet. Rec. 90, 465-468 (1972).

6. Spongiform Encephalopathy Advisory Committee Transmissible Spongiform Encephalopathies - A Summary of Present Knowledge and Research (HMSO ISBN 0-11-242-9874, London, 1995).

7. Brown, P. in Prion Diseases (eds Baker, H. F. \& Ridley, R. M.) 139-154 (Humana, Totowa, 1996)

8. Palmer, M. S., Dryden, A. J., Hughes, J. T. \& Collinge, J . Nature 352, 340-342 (1991).

9. Telling, G. C. et al. Proc. Natl Acad. Sci. USA 91 9936-9940 (1994).

10. Hunter, N., Goldmann, W., Smith, G. \& Hope, J. Vet. Rec. 135, 400-403 (1994).

11. Hau, C. M. \& Curnow, R. N. Phil. Trans. R. Soc. Lond. B 351, 913-920 (1996).

\section{The problem with MAFF}

SIR - It is encouraging to see your leading article $^{1}$ asking for a change in policy by the Ministry of Agriculture, Fisheries and Food (MAFF) over data on bovine spongiform encephalopathy (BSE).

Although it probably represents only a minor part of total research, MAFF has a history of suppressing scientific information it does not like, either by banning publication by its research staff or suggesting to those outside that publication of certain MAFF-sponsored research might jeopardize further funding. This is probably a cultural problem within MAFF arising from the view that the role of scientific civil servants is to support politicians. As a result, science must be made to fit policy (which may be based on dogma), rather than policy being based on scientific understanding.

Dogma overriding scientific understanding is well illustrated by MAFF's attitude to the sheep industry. The United Kingdom has the largest and most successful sheep industry within the European Union (EU). Approximate values ${ }^{2}$ indicate that there were 43,901,000 sheep and lambs in June 1993, which provided a total income, including that to sheep-associated industries, of about $£ 3.5$ billion a year, and gave employment to about 250,000 people. The EU guaranteed-support payment in 1993 was $£ 422$ million, but MAFF spends almost nothing on the most important lowland disease of sheep, infection with nematodes.

Because nematodes resistant to all three groups of anthelmintics have been found in the United Kingdom ${ }^{3}$, sooner or later the sheep industry will be forced to contract when total anthelmintic failure occurs on sheep farms. Not only is MAFF not interested, but the EU does not fund research in this area because "worms do not matter". MAFF will not pay directly, and appears opposed on political grounds to levies. Levies are the only other way of collecting money for essential research and farmer education programmes that are urgently required.

The only people who can change attitudes in MAFF are Members of Parliament. Scientists and farmers alike should write to their MPs and demand freedom of information on quality research sponsored by MAFF. In addition, because of changing diseases, MPs must insist on a national agricultural programme that is based on maintaining wealth generation (and food supplies) through increased research on disease control in plants and animals.

\section{Gerald C. Coles}

Department of Clinical Veterinary Science, University of Bristol, Langford House,

Bristol BS18 7DU, UK

1. Nature 383, 463 (1996)

2. Sheep UK (National Sheep Association, Malvern, 1995).

3. Coles, G. C., Warner, A. K. \& Best. J. R. Vet. Rec. 139 , 299 (1996).

\section{corres@nature.com}

Letters submitted for Correspondence can be e-mailed to corres@nature.com, but please send only items intended for the Correspondence section to this address. 